\title{
A Novel Antimicrobial Peptide on the Ocular Surface Shows Decreased Expression in Inflammation and Infection
}

\author{
Asiya Abedin, ${ }^{1,2}$ Imran Mohammed, ${ }^{1,2}$ Andrew Hopkinson, ${ }^{1}$ and Harminder S. Dua ${ }^{1}$
}

Purpose. Antimicrobial peptides (AMPs) are cationic host defense peptides with microbicidal and cell-signaling properties. They show promise as potential therapeutic agents. In the present study, a $\beta$-defensin AMP gene was isolated from the ocular surface for the first time, and its expression was characterized in the presence of ocular inflammation and/or infection.

Methods. Total RNA was obtained from impression cytology samples of the conjunctiva and cornea of normal patients and of those with bacterial, viral, acanthamoeba, or dry eye disease. The expression of the $\beta$-defensin AMP DEFB-109 was determined by using reverse transcription-polymerase chain reaction (RT-PCR). Relative quantification of the gene in the various groups was performed by means of real-time PCR.

Results. DEFB-109 was constitutively expressed in all samples. The gene showed significantly decreased expression in the presence of all types of inflammation/infection. Reduced expression featured most prominently in acanthamoeba infection; the least change from normal was in dry eye.

Conclusions. The discovery of $D E F B-109$ on the ocular surface enhances our knowledge of the profile of AMPs at this important mucosal surface. The fact that its expression is significantly reduced in both inflammatory and infective ocular surface disease reflects not only an intimate balance between this host defense gene and microbes but indicates a role other than purely microbicidal. This discovery will enable the mechanisms behind the intriguing phenomenon of reduced gene expression of an AMP in disease states to be uncovered. (Invest Ophthalmol Vis Sci. 2008;49:28-33) DOI:10.1167/iovs.07-0645

$\mathrm{T}$

he importance of vision in the survival of a species and the exposed location of the eyes is the likely reason for a very full repertoire of antimicrobial activities at the ocular surface. Antimicrobial peptides (AMPs) feature prominently among these. AMPs are small cationic polypeptides found in plants, invertebrates, and vertebrates. They exhibit microbicidal prop-

From ${ }^{1}$ The Larry A. Donoso Laboratory for Eye Research, Academic Division of Ophthalmology, University of Nottingham, Nottingham, United Kingdom.

${ }^{2}$ Contributed equally to the work and therefore should be considered equivalent authors.

Supported by a grant from the Royal Blind Asylum and School/ Scottish National Institution for the War Blinded and Royal College of Surgeons of Edinburgh, UK, and the British Eye Research Foundation (Fight for Sight).

Submitted for publication May 31, 2007; revised August 22, 2007; accepted November 26, 2007.

Disclosure: A. Abedin, None; I. Mohammed, None; A. Hopkinson, None; H.S. Dua, None

The publication costs of this article were defrayed in part by page charge payment. This article must therefore be marked "advertisement" in accordance with 18 U.S.C. $\$ 1734$ solely to indicate this fact.

Corresponding author: Harminder S. Dua, Division of Ophthalmology and Visual Sciences, Eye ENT Centre, Queens Medical Centre, University Hospital, Nottingham NG7 2UH, UK;

harminder.dua@nottingham.ac.uk. erties against bacteria, ${ }^{1,2}$ fungi, mycobacteria, ${ }^{3}$ yeasts, ${ }^{4}$ and enveloped viruses. $^{2}$ AMPs are effectors of innate immunity ${ }^{5}$ found in mammalian neutrophils and various epithelia. They also bridge innate and adaptive immunity by participating in cell signaling ${ }^{6}$ and acting as chemoattractants for immature dendritic and $\mathrm{T}$ cells. ${ }^{7}$ They have a multitude of functions on the ocular surface, as elsewhere. Wound healing and protection from infection appear to be important functions of some AMPs, such as $L L-37$, and the eye is a particular case in point. ${ }^{8}$ The AMPs even have retinal trophic and antiangiogenic properties potentially making them attractive agents for treatment of macular degeneration. ${ }^{9}$ Increased AMP production in human tears has been found to be protective after ocular surface surgery, ${ }^{10}$ and within the eye AMPs suppress endotoxin-induced uveitis. ${ }^{11}$ Sometimes their presence is undesirable as when upregulation of $H B D 2$ is associated with the ocular irritation of non-Sjögren's dry eye. ${ }^{12}$ They belong to one of three groups, $\alpha$-, $\beta$-, and $\theta$-defensins, but only the first two have been isolated in humans. ${ }^{13}$ Human $\beta$-defensin 1 (HBD1) is known to be constitutively expressed, ${ }^{14,15}$ whereas $H B D 2$ is inducible by inflammation. ${ }^{16}$ Both these and other AMPs have been found to be expressed at various sites ${ }^{7,8}$ in addition to the eye. ${ }^{17-20}$ They have been found to increase the antimicrobial property of contact lens cleaning solutions ${ }^{21}$ as well as that of corneal storage media. ${ }^{22}$ Topical application of AMPs is considered to have considerable therapeutic potential. ${ }^{23-26}$ Therein lies the importance of any new AMP found to be expressed on the ocular surface; the hidden Markov model of the human genome and EST libraries together identify 28 novel $\beta$-defensin-like genes. However, the AMP DEFB-109 has not been reported in ocular cells. We report for the first time the constitutive expression of DEFB-109 in ocular surface cells obtained by impression cytology. Furthermore, we note a significantly reduced expression of DEFB-109 in impression cytology specimens obtained from the ocular surface in the presence of infection and dry eye. This reduced expression was demonstrated by real-time PCR (quantitative PCR [QPCR]) of the DEFB-109 gene in bacterial, viral, and acanthamoeba ocular infection as well as dry eye.

\section{MeTHODS}

The research was approved by the local ethics committee and the Research and Development Department of the National Health Service Trust. All research was conducted in accordance with the tenets of the Declaration of Helsinki.

\section{Sample Collection}

Informed consent was obtained before sample collection. Ocular surface cells were collected from normal eyes of patients coming for evaluation before cataract surgery $(n=3)$ and from persons with bacterial infection $(n=3)$, viral infection $(n=3)$, Acanthamoeba spp. keratitis $(n=3)$ and dry eye disease $(n=3)$. Corneal and conjunctival cells were collected by impression cytology. Hydrophilic 13-mm filter paper discs of mixed cellulose esters and pore size $0.45 \mu \mathrm{m}$ (Millipore Corp., Bedford, MA) were used. A hemidisc of filter paper was applied 
TABLE 1. Details of the Housekeeping and DEFB-109 Genes and Their Primers

\begin{tabular}{|c|c|c|c|c|}
\hline Genes & $\begin{array}{l}\text { Accession } \\
\text { Number }\end{array}$ & Primer & Primer Sequence & $\begin{array}{l}\text { Amplicon } \\
\text { Size (bp) }\end{array}$ \\
\hline$H P R T$ & NM_000194 & $\begin{array}{l}\mathrm{F} \\
\mathrm{R}\end{array}$ & $\begin{array}{l}5^{\prime}-\text { tgatagatccattcctatgactgtaga- }{ }^{\prime} \\
5^{\prime}-\text { agacattctttccagttaagttgag- }{ }^{\prime}\end{array}$ & 126 \\
\hline DEFB-109 & NM_001037380 & $\mathrm{F}$ & $\begin{array}{l}5^{\prime}-\text { cccagtaagaggtggtttgg- } 3^{\prime} \\
5^{\prime}-\text { gcaggcaccaatttgatctt- } 3^{\prime}\end{array}$ & 106 \\
\hline
\end{tabular}

to the ocular surface of interest with a fine nontoothed forceps after the eye was adequately anesthetized with amethocaine $(0.5 \%)$ or benoxinate $(0.4 \%)$ drops. Then, the membrane was "peeled" off and stored (Buffer RLT; RNeasy Minikit; Qiagen, Crawley, UK) at $-80^{\circ} \mathrm{C}$. To ensure maximum cell recovery, each area was sampled twice.

\section{Testis}

PCR-ready human testicular cDNA (0.5 ng/ $\mu \mathrm{L}$; Ambion, Huntingdon, UK) was used as a control template for the PCR and QPCR experiments.

\section{Placenta Collection}

Fetal membranes were procured from consenting patients undergoing elective caesarean section near term and delivering healthy infants and were processed according to established procedures in our laboratory. ${ }^{27}$ Fresh placental samples were collected and RNA extracted. These were used as the control for conventional PCR.

\section{Peripheral Blood Monocytes}

Peripheral blood monocytes were isolated by established methods. ${ }^{28}$ These were also used as the control for conventional PCR.

\section{Isolation of RNA and cDNA Synthesis}

Total RNA was extracted from the corneal and conjunctival impression cytology samples, as well as placenta and PBMCs using a commercial kit (RNeasy Minikit and Qiashredder columns; Qiagen) according to the manufacturer's instructions. Ethanol precipitation of RNA from several pooled samples from each category was performed for those samples in which the RNA concentration was below $44 \mathrm{ng} / \mu \mathrm{L}$, as described by Weichenhan (http://www.science.ngfn.de.index-455.htm).

Reverse transcription of all RNA samples to first-strand CDNA was performed (SuperScript III Reverse Transcriptase; Invitrogen, Paisley, UK) according to the manufacturer's protocol (but replacing RNaseOUT with SuperaseIn; Ambion) and using random hexamer primers (Promega, Southampton, UK).

\section{Polymerase Chain Reaction}

Primer sequences for each gene (Table 1) were designed based on sequences retrieved online from the Universal Probe Library (www. probelibrary.com, Roche Diagnostics, Basel, Switzerland) and ordered through MWG-Biotech (Covent Garden, London, UK). Each reaction was prepared with a commercial buffer (final concentrations: $60 \mathrm{mM}$ Tris/ $\mathrm{HCl}$ [pH 8.5], $15 \mathrm{mM}\left(\mathrm{NH}_{4}\right)_{2} \mathrm{SO}_{4}$ and $2 \mathrm{mM} \mathrm{MgCl}_{2}$; [Invitrogen]), dNTPs (0.25 mM final concentration; Invitrogen), $0.01 \%$ (vol/vol) Tween 20 (Sigma-Aldrich, Dorset, UK), $500 \mu \mathrm{M}$ of each primer (MWGBiotech), 0.5 U Taq DNA polymerase (Amplitaq Gold; Applied Biosystems Inc., Warrington, UK), and $0.5 \mu \mathrm{L}$ first-strand cDNA, in a total volume of $25 \mu \mathrm{L}$. Reactions underwent an initial cycle at $95^{\circ} \mathrm{C}$ for 15 minutes followed by 37 cycles of $94^{\circ} \mathrm{C}$ for 30 seconds, $58^{\circ} \mathrm{C}$ for 1 minute 30 seconds, $72^{\circ} \mathrm{C}$ for 2 minutes, and a final incubation at $72^{\circ} \mathrm{C}$ for 20 minutes. cDNA quality was assessed by PCR with primers targeted to hypoxanthine guanine phosphoribosyltransferase (HPRT, GenBank accession no. NM_000194; MWG-Biotech).

\section{Gel Electrophoresis Analysis}

The products of each PCR were analyzed on ethidium-bromide-stained $1 \%$ (wt/vol) agarose gels. All samples were positive for HPRT primers and were analyzed further by QPCR.

\section{Sequencing of Gene of Interest}

We sequenced the DNA bands appearing on the gels to confirm the product of interest (Fig. 1). An impression cytology sample from a normal individual was run in duplicate, and the two DNA fragments obtained were excised from the agarose gel and pooled, and the manufacturer's (QIAquick Gel Extraction Kit; Qiagen) protocol was used for elution of the DNA. The sample was then air-dried and sent for sequencing (MWG-Biotech) using the reverse primer for DEFB-109.

\section{Real-Time QPCR}

Real-time QPCR analysis was performed using DEFB-109 and HPRT primers (MWG Biotech) to allow calculation of the relative abundance of transcripts.

Reactions were prepared with $12.5 \mu \mathrm{L} 2 \times$ PCR master mix (Brilliant SYBR Green QPCR Master Mix; Stratagene, Amsterdam, The Netherlands), $500 \mu \mathrm{M}$ final concentration of each primer, $0.75 \mu \mathrm{L}$ reference dye (Stratagene), and $5 \mu \mathrm{L}$ of each cDNA $(10 \mathrm{ng} / \mu \mathrm{L})$ in a final volume of $25 \mu \mathrm{L}$. HPRT was used as the reference gene. All reactions were run in a real-time PCR system (Mx3005P; Stratagene). A standard curve was
Figure 1. Sequence of DEFB-109 gene confirmed by gel extraction and purification from one of our samples (normal conjunctival impression cytology sample). The underlined sequence within the gene is the sequence of interest.
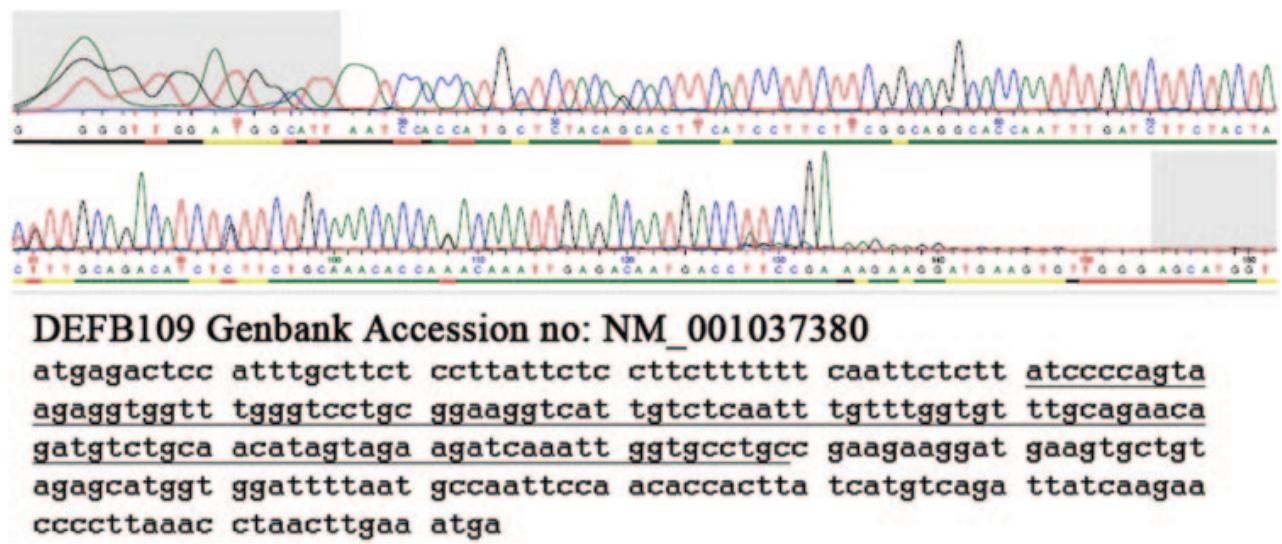

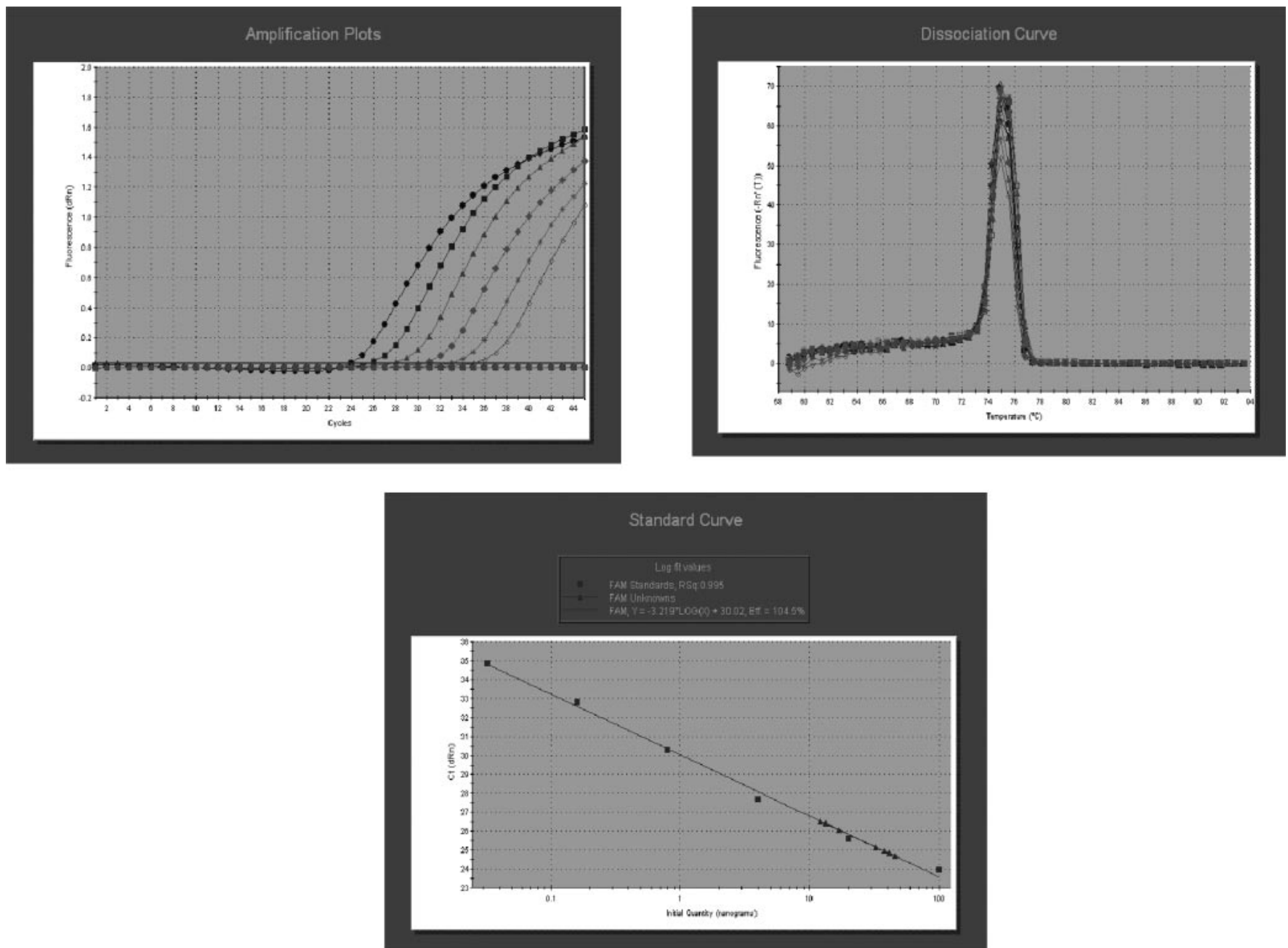

FIGURE 2. The amplification curve, dissociation curve, and standard curve obtained for HPRT in real-time PCR experiments.

generated by fivefold serial dilutions of human reference total RNA (Stratagene), concentrations of which were adjusted to allow the values of "unknown" samples to fall between their extremes. Experiments were optimized such that PCR efficiencies for the reactions fell between $90 \%$ and $110 \%$ and the standard curve slope was between -3.1 and -3.5 . Target and endogenous reference gene PCR efficiencies obtained were similar (Figs. 2, 3). Primer concentrations and annealing temperature were optimized to eliminate any confounding primer-dimers. Each standard curve was obtained by running the experiment in triplicate, and control and unknown samples were run in duplicate. Results are representative of three such experiments. Each plate was run at $95^{\circ} \mathrm{C}$ for 15 minutes, then 45 cycles of $95^{\circ} \mathrm{C}$ for 30 seconds, $58^{\circ} \mathrm{C}$ for 30 seconds, and $72^{\circ} \mathrm{C}$ for 30 seconds, followed by dissociation at $95^{\circ} \mathrm{C}$ for 1 minute, $58^{\circ} \mathrm{C}$ for 30 seconds, and $95^{\circ} \mathrm{C}$ for 30 seconds

\section{Statistical Analysis of Real-Time PCR Data and Relative Quantitation of Gene Expression}

The standard curve method ${ }^{29}$ was used to calculate relative quantities of gene expression in the different disease groups compared with the control group, using HPRT as the endogenous reference gene. Similar PCR efficiencies for the DEFB-109 and HPRT genes enabled relative quantitation of transcripts by the Pfaffl method, ${ }^{30}$ so that the normalized DEFB-109 gene expression in each of the samples was calculated by the formula $2^{-\Delta \Delta C T}$. A greater normalized $C_{T}$ indicated a higher level of gene expression. Commercial software (Prism, ver. 4.00 for Windows; GraphPad Software, San Diego, CA) was used to analyze the data. The Kruskal-Wallis nonparametric statistical analysis test was applied assuming a non-Gaussian distribution of data

\section{Results}

\section{RT-PCR Analysis of Expression of DEFB-109}

RT-PCR showed the expression of DEFB-109 to be constitutive; $1 \%$ agarose gel electrophoresis was positive for the gene in all tissues. Placental tissue showed a comparatively low level of gene expression. Impression cytology samples from all disease groups showed clear expression of DEFB-109, as did the control samples (Fig. 4).

\section{Real-Time Quantitative PCR Analysis of Expression of DEFB-109}

We ran three experiments for each of the groups of normal, bacterial, viral, dry eye, and acanthamoeba specimens. Each of the three real-time PCR experiments were run in duplicate with appropriate fivefold serially diluted standards obtained from human reference total RNA (Stratagene). All samples showed expression of the gene of interest in a constitutive manner, and quantitative values of expression were obtained (Table 2). Significantly reduced expression of DEFB-109 was noted in samples obtained from all four patient groups compared with normal samples. The reduction in quantitative expression of the $D E F B-109$ gene was in the following order: dry 

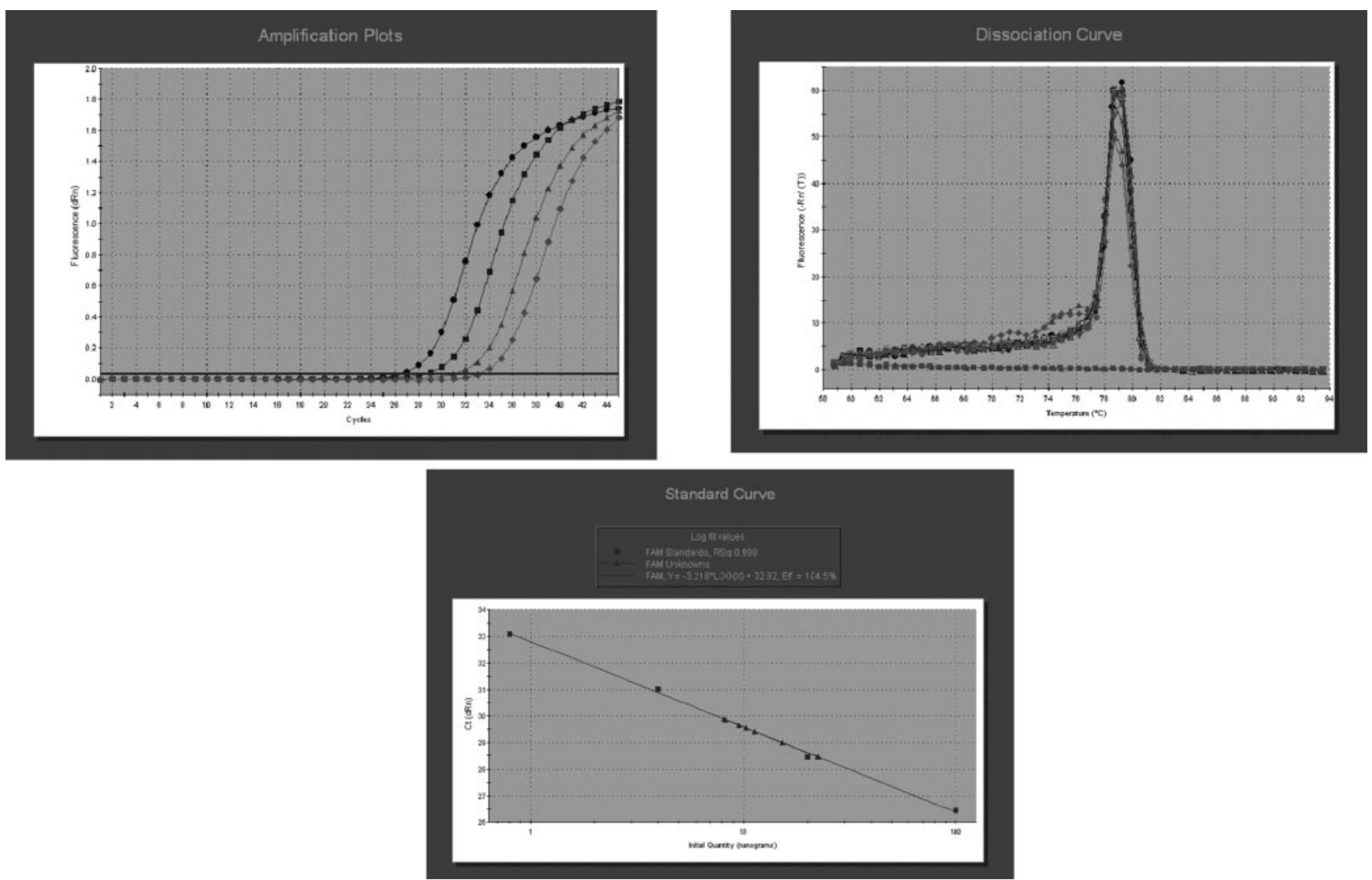

FigurE 3. The amplification curve, dissociation curve, and standard curve obtained for DEFB-109 in real-time experiments.

eye, bacterial and viral infections, and acanthamoeba infections, with dry eye showing the least and acanthamoeba the most reduction. Testis specimens (positive control) showed high expression of this defensin (data not shown).

The downregulation of $D E F B-109$ in all disease groups was significant $(P=0.0399$, or $P \leq 0.05)$. Average gene expression levels in each group were also reduced in diseased compared with normal specimens (Fig. 5).

\section{Discussion}

The conjunctiva and cornea are ideally positioned as the first line of defense in the eye, and it is for this reason that the repertoire of $\beta$-defensins expressed therein warrants thorough study, to understand conclusively the role of these surfaces in innate and acquired immunity. Our discovery of DEFB-109 on

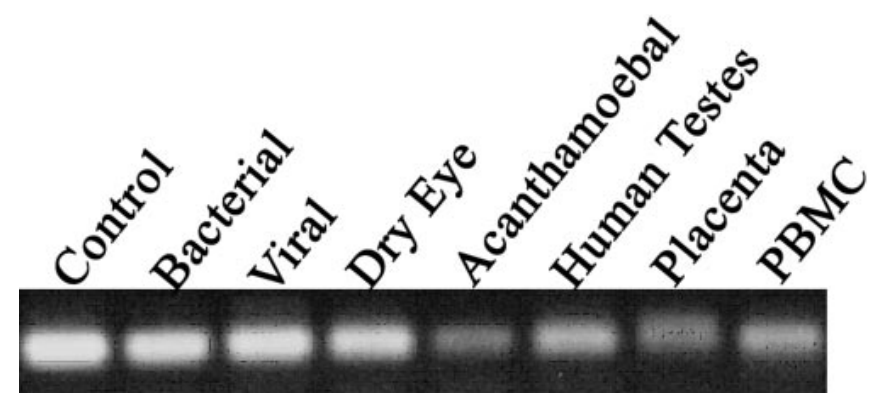

Figure 4. Agarose gel (1\%) electrophoresis after RT-PCR to illustrate the constitutive nature of $D E F B-109$ expression in a variety of tissue. The first five lanes from the left are impression cytology samples. Control signifies an impression cytology sample from a normal eye. the ocular surface expands current knowledge of the repertoire of ocular surface AMPs. The promise of AMPs as therapeutic agents, either alone or as adjuvants to host modulatory factors and standard antimicrobial therapies, further underscores the importance of understanding the full complement of AMPs at this important mucosal surface. The physiological significance of newer AMPs and the nonmicrobicidal functions of all AMPs must be understood before this potential can be realized.

There are approximately 900 AMPs known to exist at various sites. We have already shown expression of a number of AMPs on the ocular surface. ${ }^{20} \alpha$-Defensin- 1 to -3 were demonstrated in neutrophils of inflamed conjunctiva and HBD1 and -2 in ocular surface epithelium. ${ }^{17,18}$ In contrast to most epithelial sites where $H B D 1$ is constitutively expressed and $H B D 2$ is inducible, at the ocular surface both these defensins are constitutively expressed. ${ }^{17,18,20}$ Other AMPs of note demonstrated at the ocular surface include $H B D 3$, liver-expressed AMPs 1 and $2(L E A P 1,-2)$ and cathelicidin $(L L 37) .^{20}$ In our earlier

TABLE 2. Relative Quantitative Expression of DEFB-109 in the Disease Groups as Compared to Normal Eyes

\begin{tabular}{|c|c|c|c|}
\hline $\begin{array}{l}\text { Samples } \\
(n=3)\end{array}$ & $\begin{array}{c}\text { Average } \\
\text { Relative Gene } \\
\text { Expression } \\
\left(2^{-\Delta \Delta C T}\right)\end{array}$ & SD & Range \\
\hline Control & 1 & 0 & $0.7-1.5$ \\
\hline Bacterial & 0.24 & 0.096 & $0.14-0.25$ \\
\hline Viral & 0.23 & 0.023 & $0.21-0.25$ \\
\hline Acanthamoeba & 0.04 & 0.02 & $0.02-0.06$ \\
\hline Dry Eye & 0.30 & 0.065 & $0.24-0.37$ \\
\hline
\end{tabular}




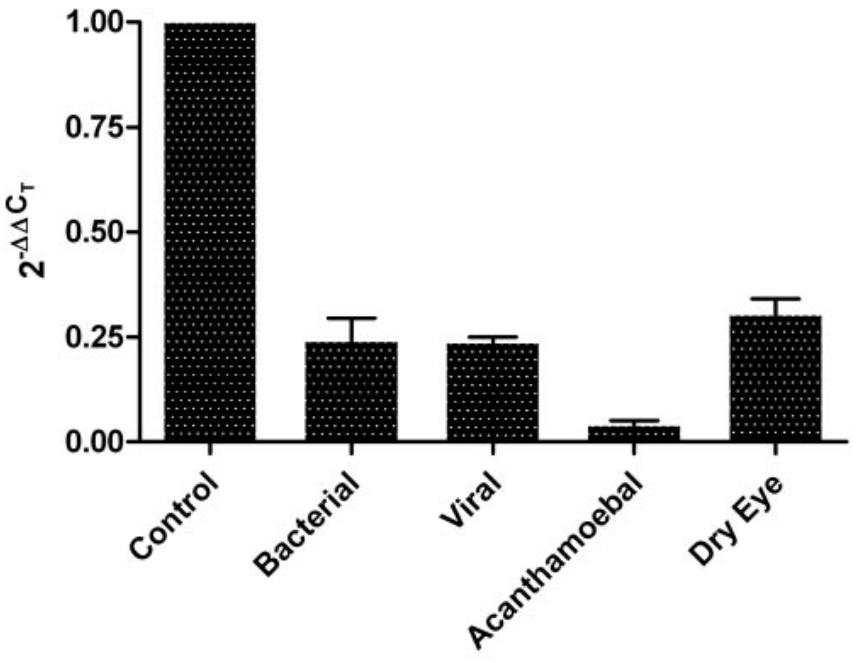

IMPRESSION CYTOLOGY SAMPLES

FIGURE 5. Relative quantification of DEFB-109 in disease versus control samples, obtained by the $\Delta \Delta \mathrm{C}_{\mathrm{T}}$ method and based on the normalized expression of $D E F B-109$ in relation to endogenous control. Data are expressed as the mean $\pm \mathrm{SD}$.

study, we noted that the highest normalized expression levels by means of real-time PCR were for $H B D 1,-2$, and -3 and LEAP2. ${ }^{20}$

Beta defensins have been demonstrated to have good activity against most bacteria and excellent activity against highly resistant bacteria, such as Pseudomonas aeruginosa and methicillin-resistant Staphylococcus aureus, with a minimum inhibitory concentration (MIC) of 1 to $4 \mu \mathrm{g} / \mathrm{mL}$ against the latter group. ${ }^{30}$

It is likely that more AMPs and their roles remain to be discovered and elucidated. Primers designed on the basis of the hidden Markov model and expressed sequence tag (EST) libraries have been used to identify numerous AMPs in the human testis, namely $H B D 3,-4, L E A P 1, L E A P 2$, and $L L 37$, and 8 of 13 putative $\beta$-defensins. However, these primers did not detect DEFB- $105,-107,-108,-118$ to $-121,-123,-125,-127$, or -129 in the ocular epithelium, ${ }^{20}$ supporting the notion that not all AMPs are expressed at all sites.

We collected cells from the conjunctival and corneal surfaces of normal persons presenting for preoperative evaluation before cataract extraction and also from patients with bacterial, viral, acanthamoeba infection, and dry eye, by means of impression cytology. Impression cytology is an established noninvasive technique of conjunctival biopsy ${ }^{31,32}$ which we have modified to improve efficacy. ${ }^{33}$ We are able to harvest the top two or three layers of ocular surface cells by this method. Each area was sampled twice to ensure an adequate sheet of cells. We used human testis cells, human placenta, and PBMC as control samples. Conventional PCR using cDNA reversetranscribed from the RNA of the above samples showed constitutive expression of $D E F B-109$ in all the tissues taken. The level of expression in placenta was less than in the other samples (Fig. 4). Quantitative real-time $\mathrm{PCR}^{34}$ was subsequently run for these samples. Premratanachai et al. ${ }^{35}$ have investigated the expression and regulation of novel $\beta$-defensins $D E F B-104$ to -114 in gingival keratinocytes. They reported the constitutive expression of DEFB-109 and its downregulation after stimulation with Candida albicans. However, their work was on cultured gingival keratinocytes rather than on cell samples, as in our study. Though others ${ }^{36}$ have detected downregulation of $L L 37$ in lower gut infection, our previous work failed to detect any such trend in ocular infections. ${ }^{20}$ Hence, the profile and behavior of AMPs of the ocular surface are distinct and unique to this site.

The expression of DEFB-109 was seen to be constitutive. This is in keeping with its close relationship with HBD1 in phylogenetic terms, as deduced by Kao et al. ${ }^{37}$ based on their genome-wide search of the hidden Markov model profile against the ORFeome peptide database (available in the public domain at www.orfeomecollaboration.org) for this and other novel $D E F B$ genes. Of interest, $D E F B-109$ showed reduced expression in each of the infected patient categories. The downregulation of the gene seen by Premratanachai et al. ${ }^{35}$ in their patients with Candida infection was proposed to be an escape strategy encouraging commensalism of the organism. ${ }^{26}$ As alluded to earlier, this phenomenon has also been seen with $H B D 1$ and $L L-37$ in human shigellosis. In this instance, it was suggested to be a bacterial virulence factor. ${ }^{36}$ Also, $H B D 2$ has been found to be decreased in human burn wounds, which may be related to the elevation of one or more of the proinflammatory cytokines $I L-1, I L-\sigma, I N F-\gamma$, and $T N F-\alpha$ in these patients. $^{38}$

It appears that infection and inflammation are associated with reduced expression of $D E F B-109$. Whether the reduced expression is a cause or effect of the infection is unclear. It remains to be seen what relationship, if any, exists between this defensin and the cytokines, which are known to be a part of the intracellular signaling cascade. At the moment there are many possibilities. Further investigation into these interactions will be necessary as more novel peptides are discovered by the aforementioned and other computational strategies.

This is the first report of expression of the novel AMP DEFB-109 on the ocular surface. It may play a role in wound healing, similar to some of the other AMPs referred to herein, and is unlikely to have a major antimicrobial effect, as it is reduced in microbial infection. Further investigation into protein expression and signaling pathways will shed light on its definite role. Nonetheless, the unequivocal downregulation of this gene in inflammation (dry eye) and even more so in infection may have important implications in understanding the link between these peptides and myriad other aspects of inflammation. On the other hand, it may represent an intriguing mechanism of immunoevasion by microbes, as Bishop and Finlay ${ }^{39}$ argue that AMPs can trigger pathogen virulence. If that is the case, strategies to reverse such evasion must be discovered.

\section{Acknowledgments}

The authors thank Rashmi Seth for technical advice and Mohammad Ilyas for use of the real-time PCR equipment.

\section{References}

1. Cullor JS, Mannis MJ, Murphy CJ, Smith WL, Selsted ME, Reid TW. In vitro antimicrobial activity of defensins against ocular pathogens. Arch Ophthalmol. 1990;108:861-864.

2. McDermott AM, Rich D, Cullor J, et al. The in vitro activity of selected defensins against an isolate of Pseudomonas in the presence of human tears. Br J Ophthalmol. 2006;90:609-611.

3. Kagan BL, Ganz T, Lehrer RI. Defensins: a family of antimicrobial and cytotoxic peptides. Toxicology. 1994;87:131-149.

4. Weinberg A, Krisanaprakornkit S, Dale BA. Epithelial antimicrobial peptides: review and significance for oral applications. Crit Rev Oral Biol Med. 1998;9:399-414.

5. Tosi MF. Innate immune responses to infection. J Allergy Clin Immunol. 116:241-249, 2005; quiz 250.

6. Yang D, Biragyn A, Kwak LW, Oppenheim JJ. Mammalian defensins in immunity: more than just microbicidal. Trends Immunol. 2002;23:291-296. 
7. Oppenheim JJ, Biragyn A, Kwak LW, Yang D. Roles of antimicrobial peptides such as defensins in innate and adaptive immunity. Ann Rbeum Dis. 2003;62(Suppl 2):ii17-ii21.

8. Huang LC, Petkova TD, Reins RY, Proske RJ, McDermott AM. Multifunctional roles of human cathelicidin (LL-37) at the ocular surface. Invest Ophthalmol Vis Sci. 2006;47:2369-2380.

9. Yamagata M, Rook SL, Sassa Y, et al. Bactericidal/permeabilityincreasing protein's signaling pathways and its retinal trophic and anti-angiogenic effects. FASEB J. 2006;20:2058-2067.

10. Zhou L, Huang LQ, Beuerman RW, et al. Proteomic analysis of human tears: defensin expression after ocular surface surgery. $J$ Proteome Res. 2004;3:410-416.

11. Ohgami K, Ilieva IB, Shiratori K, et al. Effect of human cationic antimicrobial protein 18 peptide on endotoxin-induced uveitis in rats. Invest Ophthalmol Vis Sci. 2003;44:4412- 4418.

12. Narayanan S, Miller WL, McDermott AM. Expression of human $\beta$-defensins in conjunctival epithelium: relevance to dry eye disease. Invest Ophthalmol Vis Sci. 2003;44:3795-3801.

13. Yasin B, Wang W, Pang M, et al. Theta defensins protect cells from infection by herpes simplex virus by inhibiting viral adhesion and entry. J Virol. 2004;78:5147-5156.

14. McCray PB Jr, Bentley L. Human airway epithelia express a betadefensin. Am J Respir. 1997;16:343-349.

15. Valore EV, Park CH, Quayle AJ, Wiles KR, McCray PB Jr, Ganz T. Human beta-defensin-1: an antimicrobial peptide of urogenital tissues. J Clin Invest. 1998;101:1633-1642.

16. Harder J, Bartels J, Christophers E, Schroder JM. A peptide antibiotic from human skin. Nature. 1997;387:861.

17. Haynes RJ, Tighe PJ, Dua HS. Innate defence of the eye by antimicrobial defensin peptides. Lancet. 1998;352:451-452.

18. Haynes RJ, Tighe PJ, Dua HS. Antimicrobial defensin peptides of the human ocular surface. Br J Opbthalmol. 1999;83:737-741.

19. Haynes RJ, McElveen JE, Dua HS, Tighe PJ, Liversidge J. Expression of human beta-defensins in intraocular tissues. Invest Ophthalmol Vis Sci. 2000;41:3026-3031.

20. McIntosh RS, Cade JE, Al-Abed M, et al. The spectrum of antimicrobial peptide expression at the ocular surface. Invest Ophthalmol Vis Sci. 2005;46:1379-1385.

21. Sousa LB, Mannis MJ, Schwab IR, et al. The use of synthetic Cecropin (D5C) in disinfecting contact lens solutions. CLAO J. 1996;22:114-117.

22. Schwab IR, Dries D, Cullor J, et al. Corneal storage medium preservation with defensins. Cornea. 1992;11:370-375.

23. Gallo RL, Murakami M, Ohtake T, Zaiou M. Biology and clinical relevance of naturally occurring antimicrobial peptides. $J$ Allergy Clin Immunol. 2002;110:823-831.
24. Ganz T. Antimicrobial polypeptides in host defense of the respiratory tract. J Clin Invest. 2002;109:693-697.

25. McDermott AM. Defensins and other antimicrobial peptides at the ocular surface. Ocul Surf. 2004;2:229-247.

26. Jin Y, Hammer J, Pate M, et al. Antimicrobial activities and structures of two linear cationic peptide families with various amphipathic beta-sheet and alpha-helical potentials. Antimicrob Agents Chemother. 2005;49:4957-4964.

27. Hopkinson A, McIntosh RS, Tighe PJ, James DK, Dua HS. Amniotic membrane for ocular surface reconstruction: donor variations and the effect of handling on TGF-beta content. Invest Ophthalmol Vis Sci. 2006; $47: 4316-4322$.

28. Boyum A. Isolation of mononuclear cells and granulocytes from human blood: isolation of mononuclear cells by one centrifugation, and of granulocytes by combining centrifugation and sedimentation at 1 g. Scand J Clin Lab Invest Suppl. 1968;97:77-89.

29. Pfaffl MW. A new mathematical model for relative quantification in real-time RT-PCR. Nucleic Acids Res. 2001;29:e45.

30. Hancock RE. Cationic peptides: effectors in innate immunity and novel antimicrobials. Lancet Infect Dis. 2001;1:156-164.

31. Egbert PR, Lauber S, Maurice DM. A simple conjunctival biopsy. Am J Opbthalmol. 1977;84:798-801.

32. Connor CG, Campbell JB, Tirey WW, Steel SA, Burke JH. Modification of impression cytology for in-office use. J Am Optom Assoc. 1991;62:898-901.

33. Singh R, Joseph A, Umapathy T, Tint NL, Dua HS. Impression cytology of the ocular surface. Br J Ophthalmol. 2005;89:16551659.

34. Gibson UE, Heid CA, Williams PM. A novel method for real time quantitative RT-PCR. Genome Res. 1996;6:995-1001.

35. Premratanachai P, Joly S, Johnson GK, McCray PB Jr, Jia HP, Guthmiller JM. Expression and regulation of novel human betadefensins in gingival keratinocytes. Oral Microbiol Immunol. 2004;19:111-117.

36. Islam D, Bandholtz L, Nilsson J, et al. Downregulation of bactericidal peptides in enteric infections: a novel immune escape mechanism with bacterial DNA as a potential regulator. Nat Med. 2001; $7: 180-185$.

37. Nakamura T, Furunaka H, Miyata T, et al. Tachyplesin, a class of antimicrobial peptide from the hemocytes of the horseshoe crab (Tachypleus tridentatus): isolation and chemical structure. $\mathrm{J} \mathrm{Biol}$ Chem. 1988;263:16709-16713.

38. Milner SM, Ortega MR. Reduced antimicrobial peptide expression in human burn wounds. Burns. 1999;25:411-413.

39. Bishop JL, Finlay BB. Friend or foe? - antimicrobial peptides trigger pathogen virulence. Trends $\mathrm{Mol}$ Med. 2006;12:3-6. 